
\title{
$\angle$ Research Square \\ Comparison of Tenofovir with Telbivudine in Preventing Hepatitis B Transmission in Mothers with High Viral Load: A Retrospective Cohort Study
}

\section{Ming Wang}

Capital Medical University Beijing Obstetrics and Gynecology Hospital

Yunxia Zhu

Capital Medical University Youan Hospital

\section{Qiumei Pang}

Capital Medical University Youan Hospital

\section{Ran Li}

Capital Medical University Youan Hospital

\section{Hua Zhang ( 13717850635@163.com )}

Beijing Youan Hospital, Capital Medical University. https://orcid.org/0000-0003-0727-7478

\section{Research article}

Keywords: mother-to-child transmission, Hepatitis B virus, alanine aminotransferase, antiviral therapy

Posted Date: January 5th, 2021

DOI: https://doi.org/10.21203/rs.2.14867/v4

License: (1) This work is licensed under a Creative Commons Attribution 4.0 International License. Read Full License 


\section{Abstract}

Background: Little data exist regarding comparison of efficacy and safety between tenofovir disoproxil fumarate (TDF) and Telbivudine (LdT) in late pregnancy to prevent hepatitis B mother-to-child transmission (MTCT) in real-world settings.

Methods: We retrospectively included HB-s antigen (HBsAg) positive mothers with HBV DNA $\geq 2 * 10^{5} \mathrm{IU} / \mathrm{mL}$ to receive TDF or LdT after gestational weeks $24 \llbracket 32$ weeks. All infants received standard immunoprophylaxis. Primary outcomes were MTCT rates at infants' age of 52 weeks and safety of TDF or LdT use. Secondary outcomes were the decline of HBV-DNA levels at delivery and rates of on-treatment and off-treatment alanine aminotransferase (ALT) elevation>2 upper limits of normal (ULN) during the study.

Results: Of 1407 women, 209 received TDF and 1198 received LdT treatment. There were no differences between mean duration of TDF and LdT treatment (TDF vs. LdT: $11.76 \pm 2.20$ weeks vs $11.64 \pm 2.79$ weeks, $\mathrm{p}=0.47)$. At birth, $213(9.8 \%)$ infants in the TDF-group were HBsAg positive, lower than $1180(20.8 \%)$ in the LdT-group ( $p<0.001$ ). Among 1405 infants (TDF/LdT=213/1192) of the 1385 (TDF/LdT=205/1180) women completed the 52-weeks study, intention-to-treat analysis indicated one infant (0.5\%) was lost to follow-up in TDF treated mothers and three $(0.3 \%)$ in LDT treated mothers $(p=0.48)$. On-treatment analysis indicated no HBsAg positive infants in the two groups. Levels of HBV-DNA decline in TDF-treated mothers were observed comparable to LdT-treated mothers $\left(4.05 \pm 0.93 \log _{10} \mathrm{lU} / \mathrm{mlvs} .3 .99 \pm 1.30 \log _{10} \mathrm{lU} / \mathrm{ml}, \mathrm{p}=0.50\right)$. TDFtreated mothers had complained more symptoms of the digestive system and less arthralgia than LdTtreated mothers. All adverse events in the two groups were grade I-II. Alanine aminotransferase (ALT) elevation(>2ULN) in TDF-treated mothers were lower than in LdT-treated mothers $(7.3 \%$ vs. $15.7 \%, p<0.05)$.

Conclusions: TDF and LdT use in late pregnancy for highly viremic mothers was equally effective in reducing MTCT. However, TDF has fewer ALT abnormalities than LdT during treatment and is the preferred choice.

\section{Background}

Mother-to-child transmission (MTCT) of hepatitis B virus (HBV) is the major cause of chronic Hepatitis B virus (CHB) which is associated with high rates of liver cirrhosis and hepatocellular carcinoma ${ }^{[1-2]}$. Although reduced from $90 \%$ to approximately $5 \%-10 \%$ with combined use of HBV vaccine and Hepatitis $B$ immunoglobulin G, MTCT remains a threat to infants born to women with high HBV viral loads $(>200,000 \mathrm{IU}$ per milliliter) and results in significant numbers of chronic infant infection and large carrier rates of HBV in South-east Asia ${ }^{[3-7]}$. Previous studies indicated that inhibiting HBV replication with lamivudine (LAM), telbivudine (LdT), or tenofovir disoproxil fumarate (TDF) during late pregnancy in highly viremic mothers could further reduce the risk of MTCT ${ }^{[8-10]}$. However, little data exist regarding the comparison of efficacy and safety between tenofovir TDF and LdT in late pregnancy on preventing MTCT of HBV.

In our previous study ${ }^{[9]}$, LdT-treated mothers had a mean serum HBV DNA decline $>4 \log 10$ copies $/ \mathrm{mL}$ at birth after $10.38 \pm 1.02$ weeks' treatment, compared to no change in HBV DNA levels for the untreated group 
$(p<0.001)$. Infants of LdT-treated mothers had lower HBV MTCT rates than infants of untreated mothers in $\mathrm{HBeAg}$ positive mothers with HBV DNA $>6 \log 10$ copies/mL. Incidence of Alanine aminotransferase (ALT) flares ( $>5$ times baseline level or $>10$ times ULN) were higher in LdT and LAM treated mothers than untreated mothers $(17.1 \%$ vs. $6.3 \%$, p 0.001$)$. In a randomized trial (RCT), TDF-treated women could achieve 3.56 $\log 10 \mathrm{IU} / \mathrm{ml}$ HBV DNA reduction at birth after $8.57 \pm 0.53$ weeks' treatment and yielded a successful result on HBV MTCT in HBeAg positive mothers with HBV DNA levels $>200000 \mathrm{IU} / \mathrm{mL} .{ }^{[10]}$ TDF-treated women had more frequent ALT elevations above the normal range than untreated mothers $(45 \%$ vs. $30 \%, p<0.05)$. However, in the real-world study about TDF, 11/143 (7.7\%) mothers had increased ALT after TDF cessation, which was lower than in the study about LdT ${ }^{[9,11]}$.

Because there is a lack of comparison on the MTCT rates in different nucleoside/nucleotide analogs (NAs) treated populations and lack of the same criteria on abnormal ALT elevation in these studies We conducted a retrospective cohort study with a sample size of 1637 women to assess the safety and efficacy of thirdtrimester use of TDF versus LdT, based on the woman-physician decision in a real-life MTCT prevention setting.

\section{Methods}

\section{Study design and Patient Selection}

We conducted a retrospective cohort study to assess safety and efficacy between TDF and LdT on MTCT in mothers with $\mathrm{CHB}$ in Beijing YouAn Hospital, China. The research site is a tertiary infectious disease hospital and devoted to preventing HBV MTCT for the last 20 years. Eligible consecutive women were retrospectively reviewed from January 1, 2012, to September 31, 2018. The study was approved by the Ethics Committee of Beijing You An Hospital, Capital Medical University (approval number: Jing-you-ke-lun-zi [2016]15-hao) in February 2016. The study was conducted according to International Conference Harmonization Good Clinical Practice guidelines and the Declaration of Helsinki.

Pregnant women were reviewed for the following eligibility criteria: age between 20 and 45 years; HBs antigen (HBsAg) and HBeAg positivity; HBV DNA levels $\geq 2 * 10^{5} \mathrm{IU} / \mathrm{mL}$; written informed consent before treatment; antiviral therapy started on oral antiviral agents between gestational age of 24 and 32; the infants were administered $200 \mathrm{IU}$ of HBlg intramuscular within 2 hours after birth and two doses of $10 \mathrm{ug}$ of recombinant HBV vaccine within 2 hours after birth, 4 and 24 weeks after birth. Key exclusion criteria included ALT $\geq 2 * U L N(U L N=40 \mathrm{U} / \mathrm{L}$ ); treatment with LAM; co-infection with hepatitis $C, D, E$, or HIV; evidence of hepatocellular carcinoma or cirrhosis; concurrent treatment with immune modulators, cytotoxic drugs or steroids; evidence of fetal deformity by ultrasound examination.

Women who received TDF treatment (300mg daily) in late pregnancy to prevent hepatitis MTCT were included in TDF- treated group and those who received LdT treatment (600mg daily) in LdT-treated group. Mothers were instructed to discontinue TDF treatment if their hepatitis B remained inactive after delivery, and mothers voluntarily selected their ways of feeding the infants after drug cessation.

\section{Data Collection and Outcome Measurements}


Demographic and clinical data were extracted from the electronic clinical records and paper charts from the clinic and inpatient services in YouAn Hospital. Data were assessed at the following time points: 4-week intervals from baseline information to childbirth: 4-8, 12, 24, and 28-52 weeks after birth. The following data from the clinic and inpatient services were collected for analysis: age, initiating administration weeks, treatment duration during pregnancy, childbirth and obstetric complications, pertinent physical findings, and laboratory information which include HBV virological markers, chemistry panel results, and imaging results.

Two primary outcomes are the rates of MTCT and the safety of TDF or LdT use until one year after birth. The rate of MTCT is defined as the proportion of infants who had serum HBV DNA levels of $>20$ IU per milliliter (i.e. above the lower limit of detection) or who were positive for hepatitis B surface antigen (HBsAg) 7-12months after birth. Rates of ALT elevation were rates of 2 times ULN during treatment or follow-up. AEs were graded according to the Common Terminology Criteria for Adverse Events (version 4.0). Cases of structural defects or other safety reports about newborns or infants were tabulated using data acquired from infants during the prenatal period up to 28 weeks of gestational age or after birth (e.g. ultrasonography examination, reports of birth defects and APGAR scores, measurements from growth charts, and development milestones). Perinatal and peripartum complications (e.g., hypertensive disorders in pregnancy, gestational diabetes mellitus, fetal growth retardation, preterm birth, premature rupture of membranes, and postpartum hemorrhage) were included in the safety analysis.

Secondary outcomes were a decline of HBV-DNA levels at birth and rates of alanine aminotransferase (ALT) elevation $>2$ upper limits normal (ULN) during the study.

\section{Statistical Analysis}

Based on two previous studies, we estimated that $17.1 \%$ of mothers had ALT elevations after LdT cessation and $7.7 \%$ after TDF cessation. ${ }^{[9,11]}$ The number of women needed to capture the difference of $9.4 \%$ adverse events was calculated to be 165 in the TDF-group and 660 in the LdT-group (1:4 matched) with a significance level of 0.05 (one-tailed). Considering a $10 \%$ dropout rate, a sample size of at least 176 in the TDF-group and 726 in the LdT-group was a reasonable estimation for the current study Intention to treat analysis was defined as analysis included all women, also those with protocol deviations. We included all infants to perform ITT analysis of the MTCT rates. Data of mothers and infants who were lost to follow-up were still included in the analysis. Infants who were lost to follow-up were counted as having treatment failure. Baseline characteristics and laboratory results were summarized using descriptive statistics, including percentages, means \pm standard deviation (SD) and $95 \%$ Confidence Intervals $(\mathrm{Cl})$. For quantitative variables, t-test was used to compare group differences. For categorical variables, chi-square test was used for group comparisons. The significance level was set at $p<0.05$; all data were analyzed by SPSS 23.0 (SPSS, IBM., New York).

\section{Results}

\section{Study Population}


A total of 1767pregnant women were reviewed and 1407 mothers were included in the study. Among those, 209 women received at least one dose of TDF and $1198 \mathrm{got}$ at least one dose of LdT, resulting in 209/1407 women in the TDF group at baseline and 1198/1407 in LdT group. Lost to follow-up after baseline consisted of 22 women, which included 18 before birth and four after birth, resulting in 1385 mothers with a 52-weeks follow-up (TDF/LdT=205/1180). There were 1409 infants (TDF/LdT=214/1195) born from 1389 mothers (TDF/LdT=206/1183) in this cohort with 20 pairs of twins, and 1405 infants completed the 52-week followup. The disposition of the participants is shown in Figure. 1. Characteristics of women at baseline are presented in Table 1. Mean ( \pm SD) gestational age at drug initiation was $27.38 \pm 1.84$ weeks (TDF) and $27.52 \pm 1.13$ weeks $(\mathrm{LdT})$. The mean (+SD) duration of treatment was $11.76 \pm 2.20$ weeks of gestational age (TDF) and $11.64 \pm 2.79$ weeks for those who received $L d T$.

\section{Efficacy assessment of TDF and LdT in MTCT}

Before birth, the decline of HBV-DNA levels in TDF-treated mothers were comparable to those treated with LdT (4.05 $\pm 0.93 \log _{10} \mathrm{IU} / \mathrm{ml}$ vs.3.99 $\left.\pm 1.30 \log _{10} \mathrm{IU} / \mathrm{ml}, \mathrm{p}=0.50\right)$. All infants received HBlg with the first dose of HBV vaccine within two hours after birth and completed the additional two vaccines conform standards of care, except for four infants who returned to the local city to complete their course but were lost to follow up. At birth, HBsAg positive rates of infants in the TDF-group were lower than in the LdT-group (9.8\% vs.20.8\%, $\mathrm{p}<0.001)$.

Among 1409 infants (TDF/LdT=214/1195) of the 1385 mothers (TDF/LdT=205/1180), 1405 infants (TDF/LdT=213/1192) completed the 52-week follow-up after birth (98.5\% retention rate). Intention-to-treat analysis indicated $0.5 \%$ (1 of 214 infants lost to follow-up) in TDF treated mothers and $0.3 \%$ in LdT treated mothers (3 of 1195 infants were lost to follow-up). No difference was observed between both groups ( $p=$ 0.483). On-treatment analysis indicated no HBsAg positive infants in both groups.

\section{Safety Assessment}

Most women tolerated treatment well without discontinuation due to AEs. During treatment, however, 18 mothers (TDF/LdT=15/3) withdrew after receiving the first dose. All withdrawals were because of family relocation to other cities, except for one LdT treated woman who experienced grade II AEs (mild skin rash and some episodes of vomiting) and voluntarily withdrew from the study.

There were 19 itemized AEs recorded based on maternal complaints, physical findings, and laboratory abnormalities. Nausea, anorexia, and dizziness occurred more often in TDF treated women. However, more mothers complained of arthralgia in LdT treated group. All AEs reported were grade I-II and there were no severe maternal AEs observed in two groups. There were no differences in the incidence of other AEs between both treatment-groups.

No differences in ALT elevations were observed between TDF and LdT-treated mothers ( $1 \%$ vs. $0.7 \%, p=0.65)$ during the treatment (Table 2). Also, no differences were found in the levels of ALT elevation between TDFand LdT-treated mothers (190.95 \pm 4.45 , vs. 165.13 $\pm 142.68, \mathrm{p}=0.82)$. As per protocol, 1379 women stopped antiviral therapy after four weeks postpartum. ALT elevations after birth occurred in 13/204 (6.4\%) women in 
TDF-group as compared to $180 / 1175(15.3 \%)$ in LdT-group $(p<0.001)$. No differences, however, were found in the mean (SD) ALT levels between both groups $(222.04 \pm 205.91$ vs. $147.78 \pm 90.86, p=0.262)$. All women had normalized values 16 weeks after birth.

No significant differences in gestational weeks at birth were observed between TDF-and LdT-treated women (39.15 \pm 1.38 vs. $39.15 \pm 1.39$ weeks, $p=0.99$ ). Also, the incidences of postpartum hemorrhage (TDF $1.9 \%$ vs. LdT 2.3\%; $p=0.96$ ) and rates of cesarean section (TDF43.9\%vs. LdT 46.8\%; $p=0.44$ ) did not differ. The majority of mothers who had cesarean section had the following top three indications: previous cesarean section, failure to progress, and fetal distress. No significant differences were found in terms of newborns' weight, height, or Apgar scores (Table1). Women did not receive amniocentesis during pregnancy. One infant in the TDF group had a fracture of the humerus. There were no differences in neonatal asphyxia, full-term low birth weight newborns, preterm birth, pathological jaundice, and pneumonia. No other severe AEs in infants were found in both groups and no differences were found in terms of infants' heights and APGAR scores. Congenital deformities were reported in $\mathrm{n}(0.3 \%)$ infants in the LdT group ( 1 infant had a unilateral cleft palate, right-hand polydactyly and 1 had sacral fissure). No congenital deformities were found in newborns of the TDF-group (Table 3). All mothers followed instructions of no breastfeeding during treatment.

\section{Discussion}

In this study, we report the data on comparing antiviral treatment with either TDF or LdT in pregnancy to prevent MTCT in highly viremic mothers. TDF or LdT are recommended in high viremic populations during pregnancy in many guidelines for the management of chronic HBV infection. There is, however, no priority recommendation because of the lack of studies on the preference of TDF or LdT ${ }^{[6,12-15]}$. We found both TDF and LdT were $100 \%$ successful to prevent MTCT in our real-life setting. Similar to the previous studies ${ }^{8-10,16-}$ 18 , our data further support the use of TDF, or LdT during late pregnancy on preventing MTCT in CHB mothers with high levels of HBV DNA ${ }^{[8-10,16-18]}$.

Many studies observed the safety profiles of LdT or TDF and antiviral treatment was tolerated well during pregnancy. ${ }^{[8-11,19-20]}$ No differences were found in the rates of fetal or infant complications between those receiving TDF or LdT antiviral treatment and those without. Previous studies, however, were underpowered to evaluate potentially small differences in birth-defect rates. Our study, with much larger sample size, identified similar AEs profiles with those published in previous studies ${ }^{[8-11,19-20]}$. Congenital deformities reported in $0.3 \%$ of infants in the LdT group were not higher than in the general population ${ }^{[21-22]}$. Although no differences in MTCT rates and birth defect rates were found between TDF-treated mother and LdT treated mothers, the rates of ALT elevations were more often in LdT treated mothers than in TDF-treated mothers.

Patients who received TDF treatment complained of more digestive system symptoms than LdT during pregnancy. However, these symptoms were mild and tolerated well. TDF treated mothers had fewer ALT abnormalities than LdT. Patients with Ldt need more frequent monitoring during treatment and after birth. TDF was safer than LdT. Ldt was suitable for patients with severe gastroenterol diseases, such as Hyperemesis gravidarum. However, there are several inevitable limitations of our study. Our study is a 
retrospective study, which needs verification of a prospective one in the future. Besides, our study only included women in an immune tolerance stage and may not be generalizable to those with ALT higher than $2 *$ ULN before treatment.

\section{Conclusion}

Our results indicated that TDF or LdT treatment yielded similar success rates in preventing MTCT in CHB mothers with HBV DNA $\geq 2 * 10^{5} \mathrm{IU} / \mathrm{mL}$ during late pregnancy. TDF had a lower rate of ALT abnormalities than LdT during the treatment and is the preferred choice.

\section{Abbreviations}

AE, adverse events; $\mathbf{A L T}$, alanine aminotransferase; CHB, Chronic Hepatitis B; HBeAg, Hepatitis B e-Antigen; HBIg, Hepatitis B immune globulin; HBsAg, Hepatitis B surface Antigen; HBV, Hepatitis B virus; TDF, tenofovir disoproxil fumarate; LdT, Telbivudine; MTCT, mother-to-child transmission; ITT, Intention-to-treat; PP, perprotocol.

\section{Declarations}

Ethics approval and consent to participate: All procedures performed in studies involving human participants were in accordance with the ethical standards of the institutional and/or national research committee and with the 1964 Helsinki declaration and its later amendments or comparable ethical standards. The study was approved by the Ethics Committee of Beijing YouAn Hospital, Capital Medical University (approval name: clinical trial of antiviral therapy in the prevention of mother to child transmission of hepatitis B at stage of middle and late pregnancy in mothers with High Viral Load; approval number: Jingyou-ke-lun-zi [2016]15-hao) at February 2016. All the patients written informed consent before treatment.

Consent for publication: Not applicable.

Availability of data and material: The datasets used and/or analyzed during the current study are available from the corresponding author on reasonable request.

Competing Interest: The authors declare that they have no conflict of interest.

Funding: The design and data collection in this study was supported by a research grant from Major project of Beijing Municipal Science and Technology Commission (grant number: D161100002716004). The writing of the manuscript, statistical analysis, and interpretation of data were supported by Beijing Hospitals Authority Talent Training Plan (grant number: QMS20191701).

\section{Author Contributions}

Dr. WM and ZH proposed the concept and designed the study. Drs ZH, WM, ZYX, PQM, and LR contributed to the acquisition of data. Dr. WM performed the statistics and interpreted the data and wrote the manuscript 
with assistance from Dr. ZH. All authors provided inputs for the manuscript. Dr. ZH performed critical revision of the manuscript. All authors read and approved the final manuscript.

\section{Acknowledgements}

We thank our research associates, including Hong We, Lingzhi Chang, Zhiqiang Zhao, Xiang Gao and Xin Zhou in the Department of Obstetrics and Gynecology, Youan Hospital Medical Center, for providing assistance with the data collection.

\section{References}

1. Lavanchy D. Hepatitis B virus epidemiology, disease burden, treatment, and current and emerging prevention and control measures. J Viral Hepat. 2004; 11: 97-107.

2. Pan CQ, Zhang JX. Natural history and clinical consequences of Hepatitis B virus infection. Int J Med Sci.2005; 2:36-40.

3. Wiesen E, Diorditsa S, Li X. Progress towards hepatitis B prevention through vaccination in the Western Pacific. 1990-2014.Vaccine. 2016; 34:2855-2862.

4. Zou H, Chen Y, Duan Z, Zhang H, Pan C. Virologic factors associated with failure to passive-active immunoprophylaxis in infants born to HBsAg-positive mothers. J Viral Hepat. 2012;19: e18-25.

5. Lee C, Gong Y, Brok J, Boxall EH, Gluud C. Hepatitis B immunisation for newborn infants of hepatitis B surface antigen-positive mothers. Cochrane Database Syst Rev. 2006; 2: CD004790.

6. Terrault NA, Bzowej NH, Chang KM, Hwang JP, Jonas MM, Murad MH. AASLD guidelines for treatment of chronic hepatitis B. Hepatology. 2016; 63: 261-83.

7. World Health Organization Western Pacific Regional Office. Eliminating mother to child transmission of HIV, hepatitis and syphilis. August.2018. (https://www.who.int/westernpacific/activities/ eliminatingmother-to-child-transmission-of-hiv-hepatitis-syphilis - 90k).

8. Xu WM, Cui YT, Wang $L$, et al. Lamivudine in late pregnancy to prevent perinatal transmission of hepatitis B virus infection: a multicentre, randomized, double-blind, placebo-controlled study. J Viral Hepat. 2009;16:94-103.

9. Zhang H, Pan CQ, Pang Q, Tian R, Yan M, Liu X. Telbivudine or lamivudine use in late pregnancy safely reduces perinatal transmission of hepatitis B virus in real-life practice. Hepatology.2014; 60:468-476.

10. Pan CQ, Duan Z, Dai E, et al. Tenofovir to prevent hepatitis B transmission in mothers with high viral load. N Engl J Med. 2016;374:2324-2334.

11. Ming Wang, Qian Bian, Yunxia Zhu, et al. Real-world study of tenofovir disoproxil fumarate to prevent hepatitis B transmission in mothers with high viral load. Aliment Pharmacol Ther. 2019; 49: 211- 217.

12. Chinese Foundation for Hepatitis Prevention and Control; Chinese Society of Infectious Diseases, Chinese Medical Association; Chinese Society of Hepatology, Chinese Medical Association. [Management algorithm for interrupting mother-to-child transmission of hepatitis B]. Zhonghua Gan Zang Bing Za Zhi. 2017;25(4):254-256. 
13. Hou J, Cui F, Ding Y, et al. Management Algorithm for Interrupting Mother to Child Transmission of Hepatitis B Virus. Clin Gastroenterol Hepatol. 2019; 17:1929-1936.e1.

14. Tong MJ, Pan CQ. An expert consensus for the management of chronic hepatitis B in Asian Americans. Aliment Pharmacol Ther. 2018; 47:1181-1200.

15. European Association for the Study of the Liver. EASL 2017 clinical practice guidelines on the management of hepatitis B virus infection. J Hepatol. 2017; 67:370-398.

16. Chen $\mathrm{HL}$, Lee $\mathrm{CN}$, Chang $\mathrm{CH}$, et al. Efficacy of maternal tenofovir disoproxil fumarate in interrupting mother-to-infant transmission of hepatitis B virus. Hepatology. 2015; 62:375-386.

17. Greenup AJ, Tan PK, Nguyen V, et al. Efficacy and safety of tenofovir disoproxil fumarate in pregnancy to prevent perinatal transmission of hepatitis B virus. J Hepatol. 2014;61:502-507.

18. Han GR, Cao MK, Zhao W, et al. A prospective and open-label study for the efficacy and safety of telbivudine in pregnancy for the prevention of perinatal transmission of hepatitis $B$ virus infection. $J$ Hepatol. 2011;55:1215-1221.

19. Han GR, Jiang HX, Wang CM, et al. Long-term safety and efficacy of telbivudine in infants born to mothers treated during the second or third trimesters of pregnancy. J Viral Hepat. 2017; 24:514-521.

20. APR. Antiviral Pregnancy Registry Interim report 1 January 1989 through 31 January 2018. www.APregistry.com. 2018: Issued in June 2018. Accessed October 2018.

21. Pei L, Zeng L, Zhao Y, Wang D, Yan H. Using latent class cluster analysis to screen high risk clusters of birth defects between 2009 and 2013 in Northwest China. Scientific Reports 2017,7:6873.

22. Zhao DD, Dai YX, Guo LQ, et al. Association between illness and mental status in pregnant women and birth defects. Zhonghua Liu Xing Bing Xue Za Zhi 2017; 38:1460-1465.

\section{Tables}

Table 1. Baseline Values of Mothers who Received TDF or LdT Treatment $(n=1407)$ 


\begin{tabular}{|c|c|c|c|}
\hline $\begin{array}{l}\text { Median (range) } \\
\text { Mothers }\end{array}$ & $\begin{array}{l}\text { TDF Treated } \\
(\mathrm{n}=209)\end{array}$ & LdT Treated & TDF vs.LdT \\
\hline Age (years) & $29.96 \pm 4.28$ & $28.04 \pm 4.14$ & $\mathrm{t}=6.124, \mathrm{p}<0.001$ \\
\hline HBV DNA ( Log10 IU/mL) & $7.93 \pm 0.67$ & $7.42 \pm 0.76$ & $\mathrm{t}=9.886, \mathrm{p}<0.001$ \\
\hline ALT ( U/L) & $20.90 \pm 12.48$ & $21.98 \pm 11.65$ & $\mathrm{t}=1.227, \mathrm{p}=0.220$ \\
\hline Initiating weeks & $27.38 \pm 1.84$ & $27.52 \pm 1.13$ & $\mathrm{t}=1.047, \mathrm{p}=0.296$ \\
\hline Administration weeks & $11.76 \pm 2.20$ & $11.64 \pm 2.79$ & $\mathrm{t}=0.713, \mathrm{p}=0.477$ \\
\hline HBsAgロIU/mla & $21797.89 \pm 21591.73$ & $9592.73 \pm 16347.30$ & $t=7.583, p<0.001$ \\
\hline $\mathrm{HBeAg} \square \mathrm{COI} / \mathrm{ml} \square$ & $1592.89 \pm 686.52$ & $1299.42 \pm 518.71$ & $t=5.736, p<0.001$ \\
\hline HBV DNA decline Log10 (IU/mL) & $4.05 \pm 0.93$ & $3.99 \pm 1.30$ & $\mathrm{t}=0.677, \mathrm{p}=0.499$ \\
\hline
\end{tabular}

*Note: **Fisher's exact test. ALT, alanine aminotransferase; HBeAg, Hepatitis B e-Antigen; HBsAg, Hepatitis B surface Antigen; HBV, Hepatitis B virus; TDF, tenofovir disoproxil fumarate; LdT, Telbivudine.

Table 2. Infants infection and ALT Flares in TDF and LdT Treated Mothers 


\begin{tabular}{|c|c|c|c|}
\hline Infants & $\begin{array}{l}\text { TDF Treated } \\
(\mathrm{n}=214)\end{array}$ & $\begin{array}{l}\text { LdT Treated } \\
(\mathrm{n}=1195)\end{array}$ & TDF vs.LdT \\
\hline Gestational age (weeks) at birth & $39.15 \pm 1.38$ & $39.15 \pm 1.39$ & $\mathrm{t}=0.011, \mathrm{p}=0.992$ \\
\hline Cesarean Section (\%) & $94 \square 43.9 \square$ & $559 \square 46.8 \square$ & $\mathrm{X}^{2}=0.594, \mathrm{p}=0.441$ \\
\hline Infants' weight (kg) & $3266.59 \pm 428.88$ & $3305.52 \pm 438.39$ & $\mathrm{t}=1.152, \mathrm{p}=0.249$ \\
\hline HBsAg+ at birth (\%) & $21 \square 9.8 \square$ & $248 \square 20.8 \square$ & $\mathrm{X}^{2}=14.06, \mathrm{p}=1.77 * 10^{-4}$ \\
\hline HBeAg+ at birth (\%) & $186(86.9)$ & $1090(91.2)$ & $X^{2}=3.92, p=0.048$ \\
\hline Detectable HBV-DNA -no. (\%) & 0 & 0 & $* * \mathrm{p}=1$ \\
\hline MTCT rate (\%) *-ITT & $1 \square 0.5 \square$ & $3 \square 0.3 \square$ & $* * \mathrm{p}=0.483$ \\
\hline MTCT rate $(\%) *-p p$ & $0 / 213$ & $0 / 1192$ & $* * \mathrm{p}=1$ \\
\hline ALT flares & $\begin{array}{l}\text { TDF-Treated } \\
(n=205)\end{array}$ & $\begin{array}{l}\text { LDT-Treated } \\
(\mathrm{n}=1198)\end{array}$ & $\begin{array}{l}\text { P-value } \\
\text { TDF vs. LdT }\end{array}$ \\
\hline ALT elevation during pregnancy, n (\%) & $2 / 205(1)$ & $8 / 1198(0.7)$ & $* * \mathrm{p}=0.647$ \\
\hline Abnormal ALT levels during pregnancy (IU/L) & $190.95 \pm 4.45$ & $165.13 \pm 142.68$ & $\mathrm{t}=0.241, \mathrm{p}=0.821$ \\
\hline ALT elevation after delivery, $\mathbf{n}(\%)$ & $13 / 204(6.4)$ & $180 / 1175(15.3)$ & $\mathrm{X}^{2}=11.56, \mathrm{p}=0.001$ \\
\hline Abnormal ALT levels after delivery (IU/L) & $222.04 \pm 205.91$ & $147.78 \pm 90.86$ & $\mathrm{t}=1.158, \mathrm{p}=0.262$ \\
\hline Any time during the study period & $15 / 205(7.3)$ & $188 / 1198(15.7)$ & $\mathrm{X}^{2}=9.923, \mathrm{p}=0.002$ \\
\hline Abnormal ALT levels during the study period $\square \mathrm{IU} / \mathrm{L}]$ & $210.75 \pm 190.65$ & $147.79 \pm 91.37$ & $\mathrm{t}=1.176, \mathrm{p}=0.261$ \\
\hline
\end{tabular}

**Fisher's exact test. ALT, alanine aminotransferase; HBeAg, Hepatitis B e-Antigen; HBsAg, Hepatitis B surface Antigen; HBV, Hepatitis B virus; TDF, tenofovir disoproxil fumarate; LdT, Telbivudine; MTCT, mother-to-child transmission; ITT, Intention-totreat; PP, per-protocol.

Table 3. Maternal Adverse Events Reported in the Study 


\begin{tabular}{|c|c|c|c|}
\hline Adverse Events N (\%) & $\begin{array}{l}\text { TDF Treated } \\
(\mathrm{n}=209)\end{array}$ & $\begin{array}{l}\text { LdT Treated } \\
(\mathrm{n}=1198)\end{array}$ & $\begin{array}{l}\text { P-value } \\
\text { TDF vs.LdT }\end{array}$ \\
\hline \multicolumn{4}{|l|}{ Grade 1-2 } \\
\hline Headache & $5(2.4)$ & $42(3.5)$ & $X^{2}=0.683, p=0.408$ \\
\hline Dizziness & $17(8.1)$ & $52(4.3)$ & $\mathrm{X}^{2}=5.491, \mathrm{p}=0.019$ \\
\hline Insomnia & $8(3.8)$ & $70(5.8)$ & $\mathrm{X}^{2}=1.380, \mathrm{p}=0.240$ \\
\hline Nausea & $31(14.8)$ & $103(8.6)$ & $\mathrm{X}^{2}=8.028, \mathrm{p}=0.005$ \\
\hline Abdominal distension & $5(2.4)$ & $23(1.9)$ & $\mathrm{X}^{2}=0.204, \mathrm{p}=0.652$ \\
\hline Anorexia & $37(17.7)$ & $65(5.4)$ & $\mathrm{X}^{2}=39.895, \mathrm{p}<0.001$ \\
\hline Arthralgia & $2(1.0)$ & $87(7.3)$ & $X^{2}=12.063, p=0.001$ \\
\hline Back pain & $3(1.4)$ & $7(0.6)$ & $* X^{2}=0.082, p=0.365$ \\
\hline Cough & $1(0.5)$ & $7(0.6)$ & $* X^{2}=0, p=1$ \\
\hline Diarrhea & $1(0.5)$ & $11(0.9)$ & $* X^{2}=0.053, p=0.818$ \\
\hline Epigastric pain & $3(1.4)$ & $15(1.2)$ & $* \mathrm{X}^{2}=0, \mathrm{p}=1$ \\
\hline Fatigue & $2(1.0)$ & $17(1.4)$ & $* X^{2}=0.044, p=0.834$ \\
\hline Lower abdominal pain & $1(0.5)$ & $15(1.3)$ & $* \mathrm{X}^{2}=0.384, \mathrm{p}=0.353$ \\
\hline Myalgia & $0(0)$ & $5(0.4)$ & $* * \mathrm{p}=1$ \\
\hline Pruritus & $1(0.5)$ & $13(1.1)$ & $* X^{2}=0.192, p=0.662$ \\
\hline Pyrexia & $2(1.0)$ & $10(0.8)$ & $* X^{2}=0, p=1$ \\
\hline Rash & $0(0)$ & $16(1.3)$ & $* X^{2}=1.760, p=0.185$ \\
\hline Creatine kinase elevation & $1(0.5)$ & $15(1.3)$ & $* \mathrm{X}^{2}=0.384, \mathrm{p}=0.535$ \\
\hline Infants & $\begin{array}{l}\text { TDF Treated } \\
(\mathrm{n}=214)\end{array}$ & $\begin{array}{l}\text { LDT Treated } \\
(\mathrm{n}=1195)\end{array}$ & $\begin{array}{l}\text { P-value } \\
\text { TDF vs.LdT }\end{array}$ \\
\hline Deformity & $0(0)$ & $3(0.3)$ & $* * \mathrm{p}=1$ \\
\hline Humeral fractures & $1(0.5)$ & $0(0)$ & $* * \mathrm{p}=0.152$ \\
\hline Neonatal asphyxia & $1(0.5)$ & $5(0.4)$ & $* * \mathrm{p}=1$ \\
\hline
\end{tabular}

Page 12/14 


\begin{tabular}{llcc}
\hline Full-term low birth weight infants & $4(1.9)$ & $15(1.3)$ & $* \mathrm{X} 2=0.156, \mathrm{p}=0.693$ \\
\hline Preterm birth & $14(6.5)$ & $64(5.4)$ & $\mathrm{X} 2=0.489, \mathrm{p}=0.485$ \\
\hline Fetal macrosomia & $7(3.3)$ & $62(5.2)$ & $\mathrm{X} 2=1.433, \mathrm{p}=0.231$ \\
\hline Pathological Jaundice & $8(3.7)$ & $47(3.9)$ & $\mathrm{X} 2=0.018, \mathrm{p}=0.892$ \\
\hline Pneumonia & $5(2.3)$ & $51(4.3)$ & $\mathrm{X} 2=1.749, \mathrm{p}=0.186$ \\
\hline
\end{tabular}

*Continuity correction; ** Fisher's exact test. TDF, tenofovir disoproxil fumarate; LdT, Telbivudine.

\section{Figures}




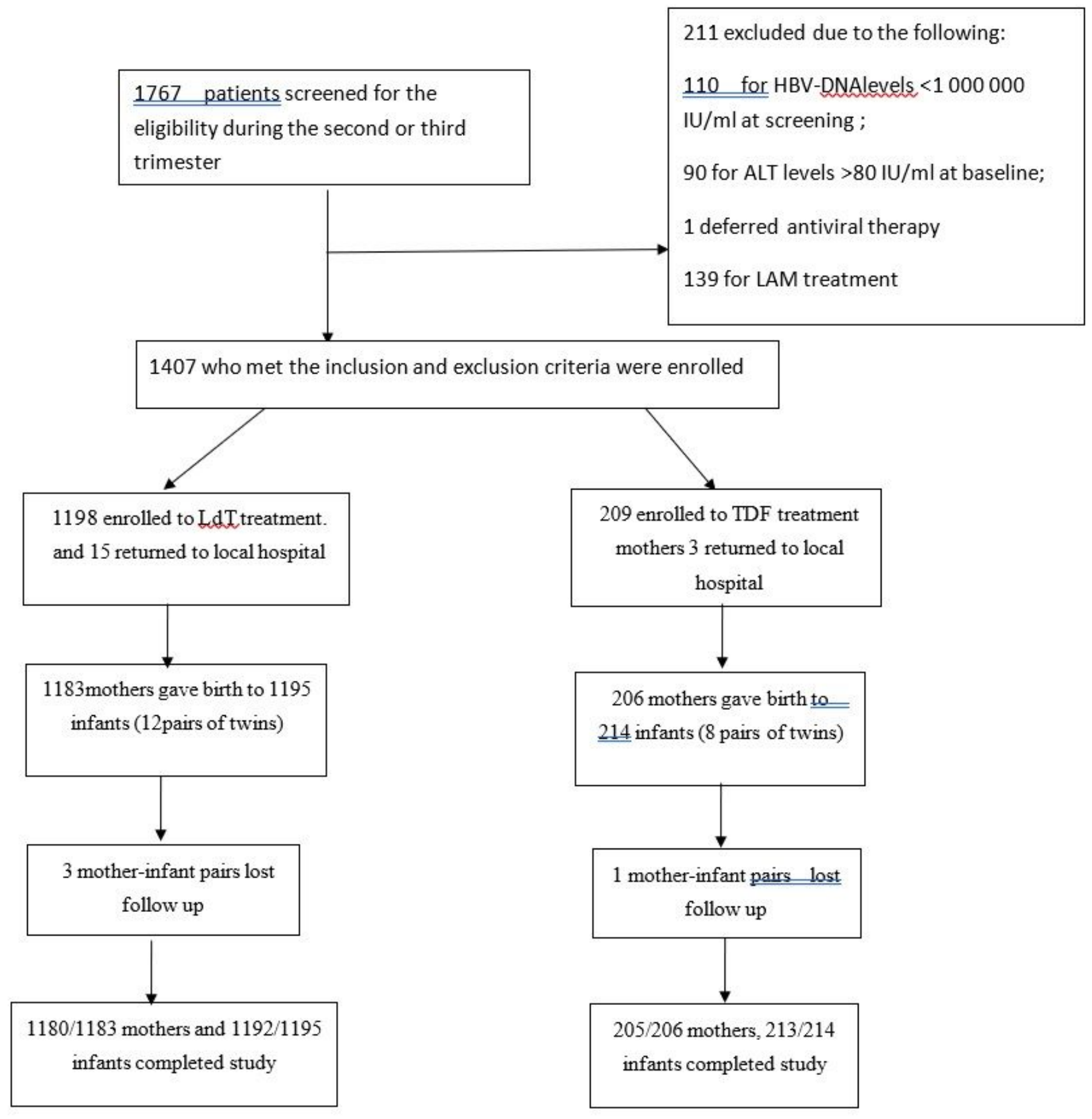

Figure 1

Disposition of mothers and infants

\section{Supplementary Files}

This is a list of supplementary files associated with this preprint. Click to download.

- STROBEChecklist.pdf 